\title{
ПРИМЕНЕНИЕ КОМПИЛЯТОРОВ В КОНЦЕПЦИИ ЦИФРОВОГО ПРАВИТЕЛЬСТВА
}

\section{APPLICATION OF COMPILATORS IN THE DIGITAL GOVERNMENT CONCEPT}

Yu. Shedko A. Shedko

Summary. It has been established that multi-agent technologies can be used to improve the multi-tier architecture of digital government. The main security problems in digital government are identified. A review of the literature on the use of compilers is given. It is concluded that organizational development and technical infrastructure development should be carried out in parallel.

Keywords: artificial intelligence, digital government, architectural modeling, information systems, compilers.

\author{
Шедько Юрий Николаевич \\ Д.э.н., доцент, Финансовый университет при \\ Правительстве Российской Федерации \\ ynshedko@mail.ru \\ Шедько Андрей Юрьевич \\ Аспирант, Начиональный Исследовательский \\ Ядерный Университет МИФИ, Москва
}

Аннотация. Установлено, что при совершенствовании многоуровневой архитектуры цифрового правительства могут использоваться многоагентные технологии. Выявлены основные проблемы безопасности в цифровом правительстве. Дан обзор литературы по использованию компиляторов. Сделан вывод, что организационное развитие и развитие технической инфраструктуры должны осуществляться параллельно.

Ключевые слова: искусственный интеллект, цифровое правительство, архитектурное моделирование, информационные системы, компиляторы.

в ролях докладчика, модератора, тьютора. Когнитивная архитектура еВІСА на основе семантической карты и моральных схем позволяет акторам использовать мимику, направление взгляда, интонацию и содержание речи для поддержания социально-эмоционального контакта с участником [8].

В России, как и в других развитых странах мира, использование искусственного интеллекта в работе органов власти реализуется в концепции цифрового правительства. Цифровое правительство - органы власти, осуществляющие принятие решений, оказание, оптимизацию, трансформацию государственных и муниципальных услуг на основе интеграции и перекрёстной обработки цифровых данных, накапливаемых во всевозможных информационных системах.

Значительную роль в становлении цифрового правительства играет архитектурная модель системы, которая отражает множество аспектов: юридических, организационных, семантических и технических представлений (программных компонентов, документации и стандартов).

Архитектурный подход при развитии электронного правительства предусматривает комплексный анализ и проектирование в соответствии с этапами:

- высокоуровневое рассмотрение электронного правительства;

- определение миссии (цели); 
Компоненты электронного правительства

\begin{tabular}{|c|c|}
\hline \multicolumn{2}{|c|}{ Компоненты электронного правительства } \\
\hline $\begin{array}{c}\text { Первая группа компонентов (используются для оценки } \\
\text { оптимизации архитектурных решений). }\end{array}$ & $\begin{array}{c}\text { Вторая группа компонентов (развивают технологические } \\
\text { и административно-операционные аспекты электронного } \\
\text { правительства) }\end{array}$ \\
\hline $\begin{array}{c}\text { электротическая миссия, цель, задачи, категории пользователей } \\
\text { формирования архитектуры }\end{array}$ & $\begin{array}{c}\text { комплексы стандартов управления архитектурой } \\
\text { электронного правительства, архитектурные модели, планы } \\
\text { развития архитектуры электронного правительства }\end{array}$ \\
\hline
\end{tabular}

Рис. 1. Состав архитектуры электронного правительства

- установление основных задач, ценностей для пользователей;

- проектирование главных компонентов конкретных информационных систем, ресурсов и сервиcOB.

Архитектура электронного правительства Российской Федерации характеризуется многоуровневой федеративно-сегментной структурой.

Свойства архитектуры электронного правительства Российской Федерации:

- гибкость и адаптивность;

- поддержка самоорганизации пользователей;

- эффективность и результативность;

- безопасность и доверие;

- ориентация на отечественного производителя;

- прозрачность изменений.

Характеристики архитектуры цифрового правительства.

1. Взаимодействие и интеграция между данными и приложениями и с различными информационными системами.

2. Наличие безопасной архитектуры для обеспечения более высокой безопасности оборудования и программного обеспечения для укрепления доверия с пользователями.

3. Возможность адаптации к изменяющимся требованиям, которые могут иметь технические, социально-экономические, правовые и / или политический характер.

4. Гибкая интеграция компонентов архитектуры улучшить согласовать бизнес-процессы и технологии.

5. Возможность многократного использования компонентов более чем в одной системе.

6. Устойчивость к изменениям в среде обслуживания.

7. Совместимость архитектуры цифрового правительства с уже существующей инфраструктурой, такой как унаследованная система и интеграция нескольких государственных учреждений в различных средах.
8. Предоставление гражданам услуги единого входа (SSO) через стандартный интерфейс или единое окно для всех электронных услуг, предлагаемых государственным сектором.

9. Прослеживаемость системных операций, выполняемых конкретными пользователями системы.

10. Удобство использования.

11. Трансграничные характеристики, например, предоставление услуг цифрового правительства в международном контексте и управленческие настройки с точки зрения $\mathrm{G} 2 \mathrm{C}$ и G2G.

12. Масштабируемость для размещения большого количества цифровых сервисов.

13. Законность, т.е. предоставление услуг цифрового правительства в соответствии с законодательством.

14. Рентабельность, т.е. архитектура должна быть реализована таким образом, чтобы развертывание и затраты на операционные ресурсы сведены к минимуму.

15. Технологическая нейтральность: архитектура должна гарантировать, что никакие компоненты, включенные в ее определение сторонников конкретных поставщиков.

16. Независимость от платформы: архитектура не зависит от конкретной технологической платформы.

17. Минимальные временные затраты на обучение государственных служащих для внедрения и использования архитектуры.

18. Понимаемость. Архитектура должна быть четко определенной и понятной со стратегической точки зрения.

19. Ориентация на гражданина. Архитектура должна поддерживать укрепление отношения между гражданами и властью.

Ориентированность на пользователя, как характеристика архитектуры цифрового правительства, включает защиту конфиденциальности пользователей, доступность для всех сегментов пользователей, мобильность (т.е. гражданин может получить доступ к услугам цифрового правительства без изменения своего географического положения). Достичь взаимодействия и клиентоориентированности для получения всех цифровых 
публичных услуг в одном месте через общие ресурсы ИТ-инфраструктуры позволяют облачные вычисления.

В большинстве архитектур (90\%) отсутствуют подробное архитектурное описание конструкции, структурных свойств и спецификаций компонентов. SOA-подход (SOA-сервис-ориентированная архитектура), ориентированный на поставщиков и технологии, характеризуется отсутствием технологической нейтральности, технологической привязкой, зависимостью от поставщиков, существенными проблемами взаимодействия.

На практике используются следующие модели цифрового правительства:

- G2C (Government-to-Citizen) Государство - Население (улучшаются и упрощаются процессы взаимодействия между населением и органами власти;

- G2B (Government-to-Business) Государство - Бизнес (обеспечивается снижение временных издержек и упрощение процедур взаимодействия между бизнес-структурами и органами власти);

- G2G (Government-to-Government) Государство Государство (обеспечивается повышение эффективности взаимодействия между государственными учреждениями, сокращаются затраты на содержание органов власти.

- G2E (Government-to-Employees) Государство Государственные служащие (обеспечивается сокращение бумажного документооборота, временных издержек и других расходов).

Большая часть схем цифрового правительства за рубежом реализует модели G2G и G2C, и большинство из них (59\%) используют сервис-ориентированную архитектуру или веб-службы. Семантические веб-сервисы, интегрированное и функционально совместимое цифровое правительство и многоуровневые схемы являются наиболее распространёнными современными архитектурами цифрового правительства. Большая часть архитектур цифрового правительства за рубежом обеспечивает высокую степень зрелости интеграции (включая горизонтальную или вертикальную). Свыше 40\% архитектур цифрового правительства за рубежом используют архитектурные стандарты, которые позволяют повторно использовать принципы проектирования.

В Европейской эталонной архитектуре взаимодействия уделяется особое внимание взаимодействию с целью оказания цифровых государственных услуг, сервис-ориентированному архитектурному дизайну, который охватывает структурные, поведенческие и управленческие аспекты функциональной совместимости. При этом не используются схемы, которые не фокусируются на взаимодействии ${ }^{1}$. Архитектурные решения, соответствующие требованиям Евросоюза, предусматривают безопасное международное цифровое взаимодействие между гражданами, предприятиями и органами государственного управления.

В экономически развитых странах Европы появляются централизованные цифровые агентства для максимизации межсекторального сотрудничества и инноваций, такие как Агентство государственного управления и электронного правительства (Difi) в Норвегии, Агентство цифровой Италии (AgID) и Агентство по оцифровке (Digst) в Дании. На уровне Евросоюза разработаны инициативы, программы и приоритеты, такие как Connecting Europe Facility (CEF) для содействия развитию высококачественных цифровых услуг путём создания многократно используемых цифровых схем, а также единый цифровой рынок для устранения препятствий на пути к онлайн-товарам и услугам. Единый цифровой рынок Евросоюза направлен на создание благоприятной среды для процветания цифровых сетей и услуг. Это достигается не только путем установления нормативных условий, но и путем предоставления трансграничных цифровых инфраструктур и услуг. При этом пользователи и заинтересованные стороны участвуют в разработке системы, государственные учреждения тесно сотрудничают с бизнесом и общественностью при создании программных решений.

Успех использования архитектуры в цифровом правительстве можно оценить с помощью архитектурных образцов - наборов соглашений, руководящих принципов и ограничений для их использования с целью формирования структуры системы.

Отметим, что веб-службы, являющиеся основой систем цифрового правительства, имеют ряд ограничений: ручное обнаружение, управление транзакциями, состав услуг, масштабируемость, надежность и устойчивость.

Рассмотрим канадский опыт применения искусственного интеллекта в органах власти. Правительство Канады в феврале 2019 года выпустило директиву об автоматизированном принятии решений. Директива предусматривает:

- оценку алгоритмического воздействия на права, здоровье или благосостояние отдельных лиц или общин; экономические интересы отдельных лиц, организаций или общин; а также постоянную устойчивость экосистем;

Официальный сайт Евросоюза URL: Код доступа: ec.europa.eu/cefdigital/ wiki/display/CEFDIGITAL/Service+Offering+Canvas+Playbook (дата обращения: 19.04.2021) 
применение стандартов прозрачности и обеспечение доступа к программным компонентам экосистем;

- обеспечение качества системы в форме: тестирования на предвзятость перед развертыванием системы; мониторинга результатов, получаемых системой; обеспечения точности и актуальности используемых данных; обеспечения обзора системы; создания потенциала внутреннего надзора и грамотности; проведения оценок рисков и планирования действий в чрезвычайных ситуациях;

- предоставление вариантов регресса для оспаривания административных решений;

- публикация регулярных отчетов об эффективности системы [13].

Исследование позволило выделить следующие ловушки (логические ошибки, нарушающие взаимодействия между техническими и социальными системами:

- кадровая ловушка - неспособность смоделировать всю систему, в отношении которой будет применяться такой социальный критерий, как справедливость;

- ловушка портативности - неспособность понять, как повторное использование алгоритмических решений рассчитаны на одного социального контекста может ввести в заблуждение, неточным или иным образом причинить вред при применении в различных условиях;

- ловушка формализма - неспособность ИИ учесть весь смысл социальных понятий, например, таких как справедливость;

- ловушка волнового эффекта - неспособность понять, как внедрение технологии в существующую социальную систему изменяет поведение и встроенные ценности уже существующей системы;

- ловушка солюционизма - неспособность признать возможность того, что лучшее решение проблемы может и не включать технологию.

Минимизировать последствия этих ловушек целесообразно на основе использования институционально-синергетического подхода с учетом сочетания субъективного и объективного начал [10]. При этом требуется адекватная задачам формирования цифрового правительства система управления кадрами [11]. Можно предположить, что органы власти будут играть доминирующую роль в цифровом обществе и обеспечат использование потенциала высоких технологий, а возможные негативные последствия будут контролироваться и предотвращаться.

При совершенствовании многоуровневой архитектуры цифрового правительства могут использоваться многоагентные технологии для поддержки адекватного разделения функций между следующими компонентами цифрового правительства: уровень доступа, уровень данных, уровень электронного правительства, уровень электронного бизнеса. Вместе с тем, использование многоуровневых и сервисно-ориентированных архитектур, сочетающих повторно используемые сервисные модули, успешно решает проблемы гибкости и совместимости, снижает сложность, стоимость разработки и коммуникаций, уменьшает время внедрения модели.

Основные проблемы безопасности в цифровом правительстве - это секретность и целостность, управление идентификацией, аутентификация и авторизация, а также предотвращение отказа. Отсутствие системной интеграции, единых стандартов описания информации, гибкости, адаптивности, совместимость, масштабируемость, возможность повторного использования, производительность, подробные архитектурные описания, структурные свойства, спецификации компонентов, технологическая нейтральность и доверие заинтересованных сторон - это основные встречающиеся проблемы в существующих архитектурах.

Следует отметить отечественные и зарубежные достижения по решению этих проблем на основе использования компиляторов - программ, преобразующих написанный на языке высокого уровня исходный текст в текст на низкоуровневом языке, близком к машинному коду. В компиляторе реализуются такие дополнительные возможности по повышению производительности как использование профиля и автоматическое распараллеливание.

В ходе исследования проведен обзор литературы по использованию компиляторов.

Классический учебник «Компиляторы: принципы, технологии и инструментарий», также известный как «The Dragon Book» («Книга с драконом») посвящен основным принципам разработки компиляторов, лексическому и синтаксическому анализу, генерации кода, а также их детальному рассмотрению [1].

В труде Харольда Абельсона и Джеральда Суссмана «Структура и Интерпретация Компьютерных программ» (SICP, Structure and Interpretation of Computer Programs) содержится описание применения функционального подхода и метапрограммирования с использованием макросов в мультипарадигменном языке программирования для решения широкого круга учебных и практических задач [12].

Растущая популярность языков программирования XXI века обусловлена привлекательной методикой за- 
действования параллелизма при многоядерных и облачных вычислениях. Авторы Odersky M., Zenger M. определяют три абстракции языка программирования для создания повторно используемых компонентов: элементы абстрактного типа, явные самотипы и модульную композицию миксинов. Совместное использование этих абстракций позволяет преобразовать произвольную сборку статических частей программы с жесткими ссылками между ними в систему многократно используемых компонентов. Преобразование сохраняет структуру исходной системы. Этот подход наблюдается в двух тематических исследованиях: структура субъект / наблюдатель и интерфейс компилятора [15].

Работа Постнова С.С. посвящёна принципам JІТ-компиляции («just-in-time»); эволюции технологий динамической компиляции программ в разных языках программирования; анализу реализации технологии JIT-компиляции программ в виртуальных машинах Java; классификации JІТ-компиляторов. Описывается базовая технология компиляции «just-in-time», её особенности и примеры её реализации в компиляторах для языка Java. Определены потенциально достижимая сложность и степень оптимизации порядка компиляции, анализируются уязвимости JІТ-компиляторов в отношении атак внедрения и переиспользования кода. Описываются меры противодействия атакам данного типа. Даётся обзор современных принципов разработки ЈІТ-компиляторов, в том числе с использованием методов машинного обучения [7].

В работе Вольфенгагена В. и др. предлагается подход к построению вычислительной модели, в которой информационные процессы представлены в рамках теорий без типов, а они, в свою очередь, рассматриваются как особые части типизированных теорий. При этом информационные процессы соответствуют параметризованным объектам метаданных, которые представляют собой конструкции переменной области. Преобразования вариабельных областей соответствуют распространению процесса, а направленное преобразование обеспечивает создание целей метаданных в форме параметризованных концепций [16].

Как пример импортозамещения интересен отечественный опыт разработки и поддержки Московским центром Спарк технологий (МЦСТ) современной компиляторной инфраструктуры и процессорной архитектуры E2K (Эльбрус 2000), основанного на VLIW (very large instruction word) подходе к проектированию процессоpa ${ }^{1}$.

Официальный сайт МЦСТ Код доступа: www.mcst.ru/ (Дата обращения 19.04.2021)
Университет Иннополис сообщил, что совместно с компаниями «Аэрофлот» и BitFury создает первую в России полностью верифицированную блокчейн-платформу. Технология основана на специализированном языке программирования, разработанном в Университете Иннополис, верифицированном компиляторе, криптографических методах и протоколах, методах верификации свойств программ. Главное преимущество инновации возможность ускоренного внедрения в практику оказания государственных и муниципальных услуг ${ }^{2}$.

Отсутствие гибкости и замедление реакции на изменения в экосистемах требуют запуска сложных ИТ-проектов. Тем не менее, многие задачи, с которыми сталкиваются ИТ-отделы, имеют стандартные решения, которые можно выразить в форме полуформализованных передовых практик и рекомендаций.

Авторы предлагают модель бизнес-процесса для государственного и муниципального управления, обогащенную семантической разметкой, которая позволяет представить рекомендации в виде полностью формализованных высокоуровневых описаний процессов. Из этих описаний можно создать конкретные модели бизнес-процессов. Авторы предлагают использовать формальные методы поиска соответствующих высокоуровневых описаний, а также рейтинг и оценку сгенерированных моделей на основе комплекса критериев.

Можно сделать вывод, что организационное развитие и развитие технической инфраструктуры должны осуществляться параллельно. В будущем новые институциональные нормы и современные технологии будут увеличивать влияние на взаимодействия, спецификации, новые услуги и улучшение существующих услуг.

Недостатки организационного дизайна и нереалистичное планирование - наиболее частые причины снижения эффективности проекта «Цифровое правительство». В связи с этим существует необходимость в проектировании эталонной архитектуры, чтобы предоставить органам власти лучшие практические знания об уже существующих архитектурах цифрового правительства, принципах их функционирования.

В заключение отметим атрибуты, которые необходимы для проектирования архитектуры цифрового правительства: безопасность, надежность, удобство использования и обслуживания, производительность, инвестиции с разумным соотношением затрат и выгод,

Объём продаж российских разработчиков в области ІоТ и блокчейна к 2024 году вырастет до 54,3 млрд. и 230,9 млрд. рублей соответственно Код доступа: media.innopolis.university/news/iot-blockchain-rostec/ (Дата обращения 19.04.2021) 
рационализация, стандартизация, функциональная совместимость, реализуемость на рынке, технологическая нейтральность, гибкость, прослеживаемость, масштаби- руемость, законность, простота обучения, конфиденциальность, доступность, прозрачность, мобильность и ответственность.

\section{ЛИТЕРАТУРА}

1. Альфред В. Ахо, Моника С. Лам, Рави Сети, Джеффри Д. Ульман. Компиляторы: принципы, технологии и инструментарий = Compilers: Principles, Techniques, and Tools. - 2 изд. - М.: Вильямс, 2008.-1184 с.

2. Лещёв С.В. Технонаука и моделируемая реальность / С.В. Лещёв // Нейрокомпьютеры: разработка, применение. 2018. — № 6. — С. 61-62.

3. Лещев С.В. Электронная культура и виртуальная реальность: третья цифровая волна НБИК-парадигмы // Вестник гуманитарного факультета Ивановского государственного химико-технологического университета. - 2014. - Т 7.— С. 5-9.

4. Методы и инструменты материального и морального стимулирования участников проектной деятельности в государственных органах исполнительной власти // Под редакцией Прокофьева С.Е. и Паниной 0.В.— Общество с ограниченной ответственностью «Центркаталог», 2019.— 192 с. Сер. Научный фонд.

5. Миндлин Ю.Б. Моделирование программного развития профессионализма персонала в условиях цифровой экономики / Крекова М.М., Киселева Е.М., Миндлин Ю.Б. // Современная наука: актуальные проблемы теории и практики. Серия: Экономика и право. 2018. № 12. С. 47-49.

6. Попадюк, Н.К. Новации во внутренней организации государственных органов: место бизнеса в их внедрении и развитии / Н.К. Попадюк, 0.С. Семкина // Экономика и предпринимательств0.— 2014.— № 7(48).— С. 300-303.

7. Постнов С.С. Обзор технологий ЛТ-компиляции //International Journal of Open Information Technologies. — 2020.— Т. 8. — № . 9.— c. 8-19.

8. Самсонович А.В. Виртуальный конференц-центр: интеллектуальная платформа с использованием когнитивной архитектуры ЕВІСА для проведения конференций и дистанционного обучения с использованием технологий VE/VR / Самсонович А.В., Чубаров А.А., Эйдлин А.А., Шедько А.Ю. // В сборнике: Восемнадцатая Национальная конференция по искусственному интеллекту смеждународным участием КИИ-2020. Труды конференции. Под ред. В.В. Борисова, 0.П. Кузнецова. Москва, 2020.- - С. 203-212.

9. Шедько Ю.Н. Влияние цифровой экономики на развитие государства, бизнеса и общества: проблемы и перспективы / Ю.Н. Шедько, М.Н. Власенко, Н.В. Унижаев // Финансовая экономика. — 2018. — № 7 (ч. 20).— С. 2475-2478.

10. Шедько Ю.Н. Факторы и условия устойчивости развития региона: синергетика взаимодействия / Ю.Н. Шедько // Вестник МГОу. Серия: «Экономика».2014. - № 4. - C 49-55.

11. Шедько Ю.Н. Антикоррупционная устойчивость государственных и муниципальных служащих в системе устойчивого развития региона / Ю.Н. Шедько // Современные проблемы науки и образования.— 2014.— №6. - С. 385; Код доступа: www.science-education.ru/120-15432 (дата 0бращения: 19.04.2021)

12. Abelson H., Sussman G.J. Structure and interpretation of computer programs. - The MIT Press, 1996. - 688 c.

13. M. Kuziemski, G. Misuraca. Al governance in the public sector:Three tales from the frontiers of automated decision-making in democratic settings. Telecommunications Policy. 44. (2020). 101976.

14. Morkovkin, D. Problems and Trends in Innovative Transformation of Russian Economy and Infrastructure Development / D. Morkovkin, S. Shmanev, L. Shmaneva // Proceedings of the 3rd International Conference on Economics, Management, Law and Education (EMLE2017), Zhengzhou, 25-26 ноября 2017 года. — Zhengzhou: Atlantis Press, 2017. - P. 10-13. - DOl 10.2991/emle-17.2017.3.

15. Odersky M., Zenger M. Scalable component abstractions //Proceedings of the 20th annual ACM SIGPLAN conference on Object-oriented programming, systems, languages, and applications. - 2005. - C. 41-57.

16. Wolfengagen, V. Capturing information processes with variable domains / V. Wolfengagen, L. Ismailova, S. Kosikov // Procedia Computer Science: Postproceedings of the 10th Annual International Conference on Biologically Inspired Cognitive Architectures, BICA 2019, Seattle, WA, 15-19 августа 2019 года. — Seattle, WA: Elsevier B.V., 2020. - P. 276-283. - DOI 10.1016/j.procs.2020.02.177.

17. Zaviyalova V.V., Norkina A.N., Mindlin Y.B. Visualization of working versions of balanced scorecard strategy maps in managing regional competitiveness // Life Science Journal. 2014. T. 11. № 11s. C. 547-549. 